0 CORPO-QUEBRADA COMO ELEMENTO DE CRIAÇÃO DE ESPAÇOS DE POSSIBILIDADES NA COMUNIDADE DA RUA DO OURO

Resumo $>$

Desde 2018, o ECOLAB investiga as possibilidades performativas de criação de Zonas Autônomas Temporárias (ZAT), na comunidade da Rua do Ouro, em São João del Rei, buscando aplicar uma metodologia própria, baseada na abordagem cartográfica-somáticoperformativa-ecopoética para a criação de espaços de possibilidades.

Palavras-chave:

Performance. Ecopoética. Evento. 


\title{
O CORPO-QUEBRADA COMO ELEMENTO DE CRIAÇÃO DE ESPAÇOS DE POSSIBILIDADES NA COMUNIDADE DA RUA DO OURO.
}

\author{
Adilson Roberto Sipueira' \\ Patrick Veniali ${ }^{2}$ \\ Aneliza Rodrigues Prado 3
}

\footnotetext{
Professor associado do curso de Teatro da Universidade Federal de São João Del-Rei (UFSJ). É professor e coordenador do Programa de Pós-graduação em Artes, Urbanidades e Sustentabilidades e professor do Programa de Pós-graduação em Artes Cênicas. ORCID: https://orcid.org/0000-00019380-6385. Email: negrados@ufsj.edu.br.

2 Estudante e pesquisador de Performance e Teatro na Universidade Federal de São João del Rei. ORCID: https:// orcid.org/0000-0002-03474418. Email: patrick_veniali@hotmail.com

${ }^{3}$ Estudante e pesquisadora de Performance e Teatro na Universidade Federal de Sao Joao del Rei. ORCID: https:// orcid.org/0000-0002-05211865. Email: anelizarp4@ gmail.com
}

\section{INTRODUÇÃO}

O Laboratório de Ecopoéticas (ECOLAB) é um laboratório de pesquisa vinculado ao Grupo Transdisciplinar de Pesquisa em Artes, Culturas e Sustentabilidade, da Universidade Federal de São João del Rei (UFSJ), que investiga a performance, a sustentabilidade e as mudanças climáticas no contexto comunitário, além de práticas pedagógicas para a preparação do ator e criação de cenas e eventos espetaculares. Em suas investigações e práticas, utiliza a abordagem cartográfica-somático-performativa-ecopoética e os conceitos de deriva (Guy Debord. 1958), análise institucional (Felix Guattari, 2001), e performance (Richard Schechner, 2006).

Desde o início de nossas atividades como bolsistas, em meados de 2018, percebemos através da análise institucional ${ }^{4}$ realizada em diversas comunidades de São João del Rei, que a Rua do Ouro, situada entre os bairros Tejuco, Alto das Mêrces e Senhor dos Montes, sofre por sua posição intermédia entre bairros, sendo essa uma das barreiras que impedem a fundação

\footnotetext{
${ }^{4}$ Aberta às leituras transversais e enfatizando a problematização coletiva, com vistas não somente a produzir conhecimento, mas também a sustentar ações institucionais que visem a mudanças efetivas [...] o desafio institucionalista concentra-se em desmontar as dicotomias sujeito-objeto, teoria-prática, opondo-se a fronteiras rígidas na definição das disciplinas, de seus métodos e objetos de pesquisa (ROMAGNOLI, Roberta, 2014, p. 45).
} 
de tradições artístico-culturais, como o teatro e as artes plásticas. Isso ocorre principalmente por ser uma região onde há uma exígua presença do estado e, tampouco, incentivo para uma autonomia comunitária. Um prato cheio para que as questões envolvendo sustentabilidade e as mudanças climáticas sejam amplificadas. Um possível exemplo é o fato da comunidade estar situada em uma região montanhosa e com pouca infraestrutura, fazendo com que qualquer chuva se torne um risco aos moradores, impossibilitando inclusive o deslocamento aos bairros vizinhos. Na Rua do Ouro não existe ponto de ônibus, o que dificulta a mobilidade urbana, sobretudo a de idosos e pessoas com dificuldade de locomoção, posto que quem necessita desse tipo de transporte tem de se locomover até o bairro Tejuco ou descer até ao Hospital Das Mercês e, dependendo das condições climáticas, o trajeto pode ser bastante perigoso.

Com base nessas reflexões, começamos a compor uma série de ações que nos levaram a criação de uma metodologia própria, utilizando o conceito de Evento Performativo, proposto pela teórica Erika Fischer-Lichte (2008) e ZAT, Zona Autônoma Temporária (1991), proposto pelo historiador e escritor Peter Lamborn Wilson, mais conhecido pelo seu pseudônimo Hakim Bey, buscando a legitimidade e visibilidade da comunidade.

\section{METODOLOGIA}

A pesquisa cartográfico-somático-performativa-ecopoética que o laboratório se propõe a investigar é uma série de conceitos estudados desde 2009 pelo professor Dr. Adilson Siqueira. Apoiado em autores como os filósofos Félix Guattari e Gilles Deleuze e a artista e professora Ciane Fernandes, esses conceitos e autores potencializam nossa busca por um fazer artístico comunitário que dialogue com diferentes contextos.

Em Mil Platôs (1996), Deleuze e Guattari nos orientam através da cartografia como método de investigação social, permitindo uma ampliação e modificação de nossa percepção das comunidades são joanenses, de modo que caminhar pelas ruas da cidade seja uma experiência criativa, inventiva, desafiadora, que desloca quem faz uso desse método para uma dimensão onde as subjetividades se conectam e se transformam no ato de cartografar. Mapear esses trajetos, utilizando a sensibilidade faz parte do rizoma. O mapa é aberto, é conectável em todas as suas dimensões, desmontável, reversível, suscetível de receber modificações constantemente. (DELEUZE, GUATTARI, 1995, p. 21).

A cartografia é um dos fundamentos do conceito de rizoma, parte central da filosofia desenvolvida pelos autores ao longo de suas publicações. Um conceito extraído da biologia, que nos diz sobre o comportamento das raízes de algumas plantas; como elas crescem e se conectam, em uma espécie de emaranhado de raízes que não se pode apontar para seu começo ou limite. É nessa direção que seguem os sistemas rizomáticos de produzir conhecimentos, $\mathrm{o}$ rizoma em si, um fluxo aberto de conexões de ideias que cria novos territórios à medida que se alastra.

Uma das características mais importantes do rizoma talvez seja a de ter sempre múltiplas entradas; a toca, neste sentido, é um rizoma animal, e comporta às vezes uma nítida distinção entre linha de fuga como corredor de deslocamento e os estratos de reserva ou de habitação. (DELEUZE, GUATTARI, 1995).

Por sua vez, a abordagem somático-performativa, elaborada pela professora da Escola de Teatro da Universidade Federal da Bahia, Ciane Fernande, se manifesta em nossa pesquisa enquanto movimento, utilizando a corporeidade para criar ações que nos conectam aos espaços e pessoas, na forma como observamos e interpretamos os nossos corpos e os corpos ao redor, na constituição das relações afetivas da cartografia, na preparação corporal das performances, na criação de eventos. Nesse sentido, o método somático-performativo pretende valorizar a prática enquanto pesquisa, de forma que, os processos e atravessamentos são consequência de uma prática viva, que se modifica ao longo de sua existência. Suas partes se relacionam com o todo, apoiada em si mesma, sendo esse um dos apontamentos de Fernandes:

O fundamental é que tenha como eixo ou 
guia a corporeidade, compreendida como um todo somático, autônomo e inter-relacional. Ou seja, que o modus operandi da pesquisa seja determinado pelas conexões somáticas criativas, ao invés de métodos determinados a priori e impostos a um objeto a ser analisado. O estudo também não precisa ser sobre performance ou temas afins, nem mesmo incluir encenação. A abordagem somática informa e se forma a partir da prática performativa processual, e vice-versa, ambas enquanto experiências metodológicas, como maneiras de ativar o estudado incógnita (daí o sentido da pesquisa), dando-lhe espaçotempo de manifest(ação) (FERNANDES, 2012, p. 3).

Ainda, a abordagem somático-performativa pretende que a pesquisa em artes seja pautada na própria criação artística, como argumento para seu desenvolvimento:

Os símbolos e as imagens nos possibilitam visualizar o movimento como um todo integrado e dinâmico. A(s) imagem(ns) mais adequada(s) a cada pesquisa emerge $(\mathrm{m}) \mathrm{du}-$ rante cada processo criativo, como parte da experimentação, e não como um modelo a priori a ser seguido. Assim, imagens, gráficos, esquemas, mapas etc. criam um todo dinâmico, coerente com o elemento-eixo da pesquisa e seus vários aspectos, meios e elementos (FERNANDES, 2012, p. 4).

$\mathrm{Na}$ sequência, o conceito "ecopoética”, cunhado pelo professor Adilson Siqueira (UFSJ), sintetiza os anseios do fazer artístico e ativista que buscamos evidenciar no Laboratório de Ecopoéticas. É esse fazer do artista ativista, ou somente artivista, que converge com as manifestações artísticas que se tem desenvolvido desde as revoltas estudantis de 1968, centrada em torno de causas específicas tais como a luta contra a industrialização cultural, o capitalismo, assumindo diversos contornos no contexto urbano (VIERA, 2007, p. 14), e que se relacionam com o mundo e seus desdobramentos sociais, ambientais e climáticos, num sentido de promoção daquilo que é sustentável e ecológico. Podemos dizer que ecopoética é o dispositivo metodológico que nos move para criação desse mundo onde a poética da vida e do fazer artístico enquanto ativismo sejam as principais práticas do artista. Ecopoética, é:

a versão artístico-estética de ecopoiesis, neologismo que foi criado (1990) pelo geneticista e biofísico canadense Robert Haynes a partir

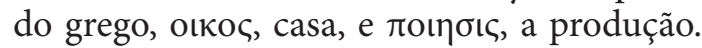
Ecopoiesis refere-se à origem, à produção de um ecossistema. No contexto da exploração espacial, Haynes descreve ecopoiesis como a "fabricação de um ecossistema sustentável em um planeta sem vida, estéril”. Ecopoiesis é um tipo de engenharia planetária e é uma das primeiras etapas da terraformação. Esta fase primária de criação de ecossistema é geralmente restrita à semeadura inicial de vida microbiana (SIQUEIRA; MONTEIRO, 2018, p.145.)

A deriva, conceito de Guy Debord (1958), esteve presente em nossas práticas cartográficas e performativas durante o começo da pesquisa, e é uma técnica do andar sem rumo. Ela se mistura à influência do cenário. Todas as casas são belas. A arquitetura deve se tornar apaixonante." (DEBORD; FILLON, 1954 apud JACQUES, 2003, p. 17). Derivar, nesse caso, tornou-se muito mais uma atitude passiva enquanto percorríamos nossos trajetos do que uma ação coletiva, mútua, performativa e urbana. Dito isso, e tendo em vista a comunidade, as relações ali estabelecidas e nossa prática cotidiana, passamos a pensar numa cartografia somática feita por um corpo que compõem os $99 \%$ da população brasileira e local ${ }^{5}$. Um corpo repleto de atravessamentos decorrentes das experiências do lugar. Um corpo que realiza muito mais uma errância do que uma deriva. Portanto, estamos falando da errância de um corpo periférico deslocando-se na quebrada, um corpo-quebrada, errante, que faz uma cartografia de si enquanto move-se pelo lugar. Nas palavras de Paola Jacques (2012)

Os errantes são, então, aqueles que realizam errâncias urbanas, experiências urbanas específicas, a experiência errática das cidades. A experiência errática afirma-se como possibilidade de experiência urbana, uma possi-

\footnotetext{
${ }^{5}$ Ao utilizarmos o termo aqui, estamos no apropriando do termo que é proposto por Arruzza, Bhattacharya e Fraser
} (2019). 
bilidade de crítica, resistência ou insurgência contra a ideia do empobrecimento, perda ou destruição da experiência a partir da modernidade [...] Mesmo vivendo um processo de esterilização da experiência hoje, esse processo, que, no caso das cidades contemporâneas, seria o processo de espetacularização urbana, não consegue destruir completamente a experiência - o que se aplica especialmente às cidades brasileiras -, embora busque cada vez mais sua captura, domesticação, anestesiamento (p. 19-20).

Assim, nossa prática passou a pautar-se por um corpo-quebrada que aguça nossa capacidade perceptiva e recebe as informações dos espaços que estamos e seus componentes, a partir das nossas próprias experiências enquanto corpos periféricos.

\section{DESENVOLVIMENTO}

A seguir, vamos discorrer sobre como ocorreu o ato de derivar e sua transformação em errância, algo que em termos metodológicos, aconteceu em duas situações: na primeira, a deriva propriamente dita, quando caminhamos por entre as ruas da região, passeando por trajetos comuns e utilizando elementos de registro cartográfico, como mapas e desenhos. Cada integrante do ECOLAB (Aneliza Rodrigues, Aretha Lima, Bruna Guimarães, Douglas Fumes, Ívyla Nascimento, João Ruas, Patrick Veniali, Wanderson Martins) registrou seus afetos da Rua do Ouro: a arquitetura, os barulhos, as cores, os cheiros, as temperaturas, os contrastes, criando assim uma espécie de "mapa afetivo", onde a experiência de derivar é registrada como em um diário. A segunda, quando ocorreu o salto para a errância, é realizada utilizando movimentos corporais desenvolvidos em salas práticas para explorar os espaços da comunidade, que será abordado no decorrer do texto. Utilizamos também a fotografia como forma de registrar nossas errâncias. Em grupo ou individualmente, percorremos os trajetos cartografados e fotografamos algumas cenas. Quando precisávamos pedir autorização aos passantes para registrar alguma imagem, aproveitávamos para conhecer a pessoa e sua história em relação a Rua do Ouro. Foi extremamente importante essa abordagem com os moradores para tornar público nossa entrada na comunidade. O interesse em expor essas imagens a disposição dos sanjoanenses nos levou a uma experiência que pôs em evidência nosso trabalho.

Logo após o começo das atividades na comunidade, mais precisamente no mês de Novembro de 2018, expusemos as imagens que obtivemos durante as derivas na III Mostra Vestígios, exposição vinculada ao Programa Interdisciplinar de Pós Graduação em Artes, Urbanidades e Sustentabilidade (PIPAUS) que acontece anualmente no Espaço Cultural da UFSJ (Solar Baronesa). Pudemos mostrar um pouco do nosso trabalho à toda comunidade sanjoanense, logo nos primeiros passos da pesquisa. Porém, o público presente na exposição foi composto, em sua grande maioria, por pessoas que não faziam parte das periferias da cidade.

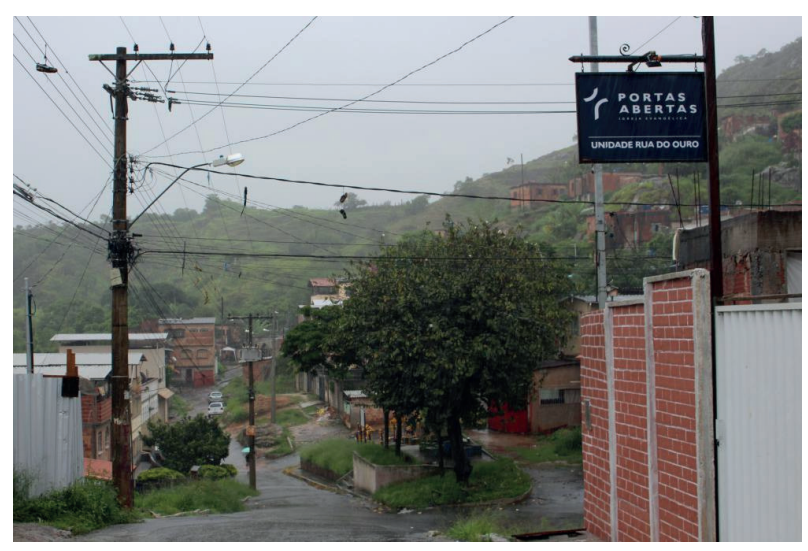

Imagem 1 - Derivas na Rua do Ouro, 2018.

Após o término da exposição, retornamos à comunidade com as fotos em mãos e fizemos uma pequena exposição na Venda do Seu Fernando, um espaço que nos ajudou a realizar todas as atividades, reuniões, e a própria pesquisa como um todo. Essa ação proporcionou uma forte guinada em nossa abordagem com relação ao modo de chegar e sair da comunidade (o famoso "saber chegar e saber sair") e de se relacionar com os moradores, além do fato de que aqueles que foram fotografados puderam levar para casa suas fotos para guardá-las como memória desses registros

O segundo momento das derivas errantes, o qual denominamos Treinamento Externo: Busca e retomada ${ }^{6}$, acontece quando colocamos 
nossos corpos nas ruas da comunidade de forma somática, como nos diz Siqueira (2000)

Busca e Retomada se propõe a ser um treinamento que aborda o ator-dançarino como um todo e utiliza elementos pertencentes às artes do ator e do dançarino, em especial as ações físicas e sonoras; as frases de movimento; propostas feitas por diversos artistas e pesquisadores sobre as técnicas para a construção da personagem e a representação não-interpretativa. (p.92)

Ou seja, constituímos ações corpóreas realizadas por um corpo previamente treinado em ambiente interno, explorando os perceptos e afetos urbanos para "ocupar" os espaços do local, criando uma composição cênico espacial de modo que os transeuntes possam olhar, observar e assistir. Neste contexto, agimos de modo que o próprio ato de observar integre o performer e espectador à performance, cuja imersão contribui para aumentar nossas relações, tanto com o local quanto com os moradores que assistem e contribuem com a ação.

Essas experiências aconteceram em momentos diferentes e na mesma região, proporcionando várias leituras do ambiente e foram primordiais nos processos de análise institucional para determinarmos, por exemplo, o melhor horário para fazermos alguma atividade em que tivéssemos as crianças como público. Foi a fusão dessas duas etapas que nos levaram à constatação de que o corpo quebrada é por si só um corpo cênico, um corpo em vida presente e performativo.

Dando prosseguimento, chegamos a mais um item de nossa metodologia: as análises institucionais, onde percebemos os pontos de tensão e os conflitos sociais instituídos na comunidade, conversando com os moradores, procurando histórias do lugar, frequentando os espaços comuns da região, estreitando a relação criada nas primeiras derivas, posteriormente errâncias. Foi dessa forma que conseguimos o apoio do "Seu Fernando", dono da venda onde realizamos a primeira exposição. Essa forma de comunicação nos ajudou a acessar as identidades psicogeográficas, que é o estudo das leis exatas e dos efeitos precisos do meio geográfico, planejado conscientemente ou não, que agem diretamente sobre o comportamento afetivo dos indivíduos. (DEBORD apud JACQUES, 2003, p. 39). Os costumes, os trajetos alternativos, os limites seguros onde as crianças podem brincar, as tradições religiosas anuais. Ou seja, tudo aquilo que faz com que a comunidade da Rua do Ouro e os indivíduos que dela participam possam ser reconhecidos como tal. Frequentamos mais algumas vezes o espaço e conseguimos perceber a diversidade de pessoas que habitam os mesmos lugares e que se identificam uns com os outros.

Obviamente, os conflitos são inevitáveis em um espaço onde a desigualdade social e suas consequências são mais evidentes, como é o caso da Rua do Ouro, onde, por exemplo, as movimentações do tráfico de drogas fazem parte da vida dos moradores. Além disso, alguns usuários de drogas, frequentam e permanecem no local após o consumo da substância ilícita. Há sempre uma pequena tensão entre as relações que se dão no dia a dia com as pessoas da comunidade. Portanto, é importante conhecer e ser conhecido para ajudar na compreensão, no contato com esses indivíduos e suas identidades psicogeográficas. É fato que todo nosso trabalho inicial teve de ser intenso para que a nossa entrada na comunidade fosse percebida por todos, inclusive por esses indivíduos.

Realizamos novamente o Treinamento Externo, trazendo a corporeidade do corpo-quebrada com esse olhar cotidiano e amigável entre nós, com o espaço e com os moradores, tentando cada vez mais fazer com que a comunidade participasse e interagisse com as performances. A curiosidade de quem vê cria situações cada vez mais interessantes e importantes para nos colocar em contato com a comunidade, pois a comunicação e a curiosidade sobre o que está acontecendo é um dos objetivos do

\footnotetext{
${ }^{6}$ A este treinamento externo, ainda em desenvolvimento no Laboratório, estamos no momento denominando TPEAC (Treinamento performativo ecopoético para a ação comunitária ecopoética), que está baseado no processo de Busca e Retomada e sobre o qual pretendemos no futuro próximo tornar publico como ele se configura.
} 


\section{Treinamento Externo.}

Retornamos mais algumas vezes à comunidade para conversarmos e pensarmos junto com os moradores que estavam presentes durante nossas visitas, algumas propostas de ações e intervenções artísticas. Começamos a idealizar um tipo de evento onde os moradores pudessem participar ativamente, tanto fazendo oficinas e atividades quanto sendo espectadores do evento.

Em Agosto de 2019, mais ou menos um ano após nossa entrada na comunidade, fizemos o primeiro evento performativo na Pracinha da Rua do Ouro. Levamos todo o material necessário para o evento, esticamos panos coloridos, colocamos música, montamos um espaço para as crianças desenharem, oferecemos uma oficina de confecção de pipas onde os oficineiros eram as próprias crianças da comunidade. Por isso, nós colhemos e cortamos bambus junto com as crianças para a confecção das hastes das pipas. Pintamos e grafitamos a frente da casa de um dos moradores mais antigos da comunidade, conhecido como "Seu Alex", fizemos apresentações com malabares de fogo e brincamos com as crianças. Foi uma tarde em que todos estavam convidados a ocupar aquela praça e aproveitar as atividades, a música, as pirofagias e momentaneamente participar de uma Zona Autônoma Temporária.

Em resumo, não queremos dizer que a TAZ é um fim em si mesmo, substituindo todas as outras formas de organização, táticas e objetivos. Nós a recomendamos porque ela pode fornecer a qualidade do enlevamento associado ao levante sem necessariamente levar à violência e ao martírio. A TAZ é uma espécie de rebelião que não confronta o Estado diretamente, uma operação de guerrilha que libera uma área (de terra, de tempo, de imaginação) e se dissolve para se re-fazer em outro lugar e outro momento, antes que o Estado possa esmagá-la. Uma vez que o Estado se preocupa primordialmente com a Simulação, e não com a substância, a TAZ pode, em relativa paz e por um bom tempo, "ocupar" clandestinamente essas áreas e realizar seus propósitos festivos. (BEY, 1985.)
Entre uma ação e outra, conversávamos com os moradores que estavam ao redor, trazendo nossas inquietações e informando sobre as ideias do nosso projeto. Ao final, expusemos mais uma sessão de fotografias registradas dias antes, colocamos as fotos em barbantes amarrados nas árvores da pracinha, e entregamos as fotografias aos moradores que estavam presentes. Recolhemos todo nosso material antes do anoitecer e partimos para casa com muitas idéias para pensar.

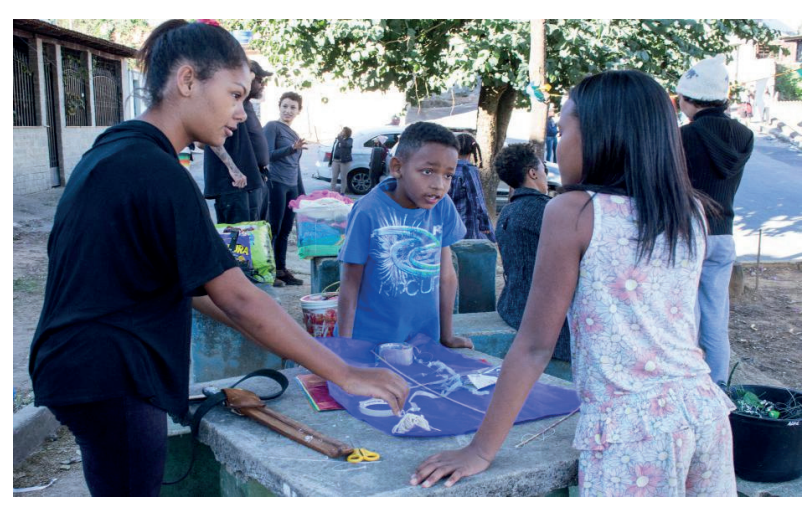

Imagem 2 - Espaços de possibilidade na Rua do Ouro

Nos reunimos em outros dias com moradores interessados em participar do projeto e que compareceram ao evento anterior para pensarmos em novas atividades comunitárias. A preocupação com as crianças e a educação básica foram os principais temas discutidos nessas reuniões, visto que não há local de lazer nem qualquer atividade recreativa próxima a Rua do Ouro. A partir daí, conseguimos começar a desenhar nossas estratégias para os próximos eventos.

No começo de Dezembro de 2019, realizamos o segundo evento na comunidade intitulado de "Sofá na Rua do Ouro, Um Espaço de Possibilidades", que contou com a presença do coletivo Sofá na Rua e do projeto "Renda-se", que impulsionaram nossas atividades. Novamente, trouxemos todo o material para que o evento pudesse ser realizado. Conseguimos estabelecer dois ambientes, sendo o primeiro localizado na Pracinha da Rua do Ouro com

\footnotetext{
${ }^{7}$ Coletivo independente composto por estudantes de teatro da Universidade Federal de São João del Rei que realiza eventos artísticos em espaços públicos.
} 
atividades similares aos do primeiro evento, tendo como novidade a oficina "Renda-se", onde os participantes aprenderam a confeccionar peças de renda a partir dos métodos criados pela oficineira Tássia Murad de Abreu ${ }^{8}$. Ainda na pracinha, o "espaço infantil" se tornou um lugar para jovens e crianças. Os brinquedos de raciocínio lógico ganharam toda a atenção do público jovem que se divertiu tentando resolver os quebra-cabeças matemáticos, escutando as músicas que mais lhes agradavam, pois disponibilizamos um amplificador para que pudessem conectar seus celulares.

O segundo espaço foi em frente à venda do Seu Fernando. Montamos um pequeno palco equipado com amplificadores, microfones e alguns instrumentos musicais. Contactamos artistas independentes da região e de fora da cidade como atrações principais, sendo uma tarde repleta de música. Tivemos sessões de freestyle com o coletivo independente "Rap na Bica" e pessoas locais que se dispuseram a pegar o microfone e expressar sua arte e suas ideias. As fotos que foram tiradas no primeiro evento ficaram expostas numa espécie de varal para novamente serem entregues aos fotografados.

As conversas com os moradores durante o evento ganharam corpo nas semanas seguintes e começamos a pensar em mais um evento de final de ano onde novas ações ecopoéticas pudessem existir. Ações onde a participação da comunidade fosse presente desde sua idealização até sua realização e, como estávamos em Dezembro, muitas ideias sobre distribuição de brinquedos, roupas e afins foram surgindo durante as reuniões com as pessoas.

Decidimos realizar uma campanha para coletar o máximo possível de doações, tanto na comunidade quanto fora dela. Tivemos poucos dias de campanha antes do evento, mas foi o suficiente para recebermos doações de várias regiões de São João del Rei, entre roupas, brin- quedos, produtos de higiene e material escolar. No dia 15 de Dezembro, dia do evento, tivemos o cuidado de realizar algumas ações - como as rodas de freestyle - na pracinha e na venda do Seu Fernando por pouco tempo, pois a nossa intenção era migrar para Fortim do Emboabas, um espaço perto dali que a Universidade pretende transformar num espaço cultural. Com o intuito de realizar mais uma ação além das doações, havia um empenho em conseguir mudas de árvores frutíferas e ornamentais, além do local para plantá-las. Especialmente com as crianças, mapeamos uma área de passagem entre a Rua do Ouro e as comunidades próximas onde o solo é propício para o plantio de qualquer muda. E como é notório a aparência de abandono no local, as mudas o tornaram um pouco mais agradável, ajudando para que a manutenção do espaço se torne um hábito. Conseguimos as plantas com o Instituto Chico Mendes de Conservação da Biodiversidade (ICMbio) e a Associação de Proteção e Assistência aos Condenados (APAC) nos auxiliou no trabalho de abrir os buracos na terra, alguns dias antes de realizarmos o evento.

Sendo assim, no dia do evento, as crianças, após as atividades na pracinhas e em frente ao bar, juntamente com seus pais, saíram em caminhada até o local escolhido e plantaram suas mudas, de modo que poderiam acompanhar o crescimento da planta em paralelo com seu próprio crescimento, fomentando o desenvolvimento de tradições sustentáveis desde cedo. Nesse terceiro evento intitulado "Vertentes do Morro, Um Espaço de Possibilidades", utilizamos o espaço Fortim do Emboabas para entregar as doações e organizar mais ações artísticas, dessa vez com uma estrutura maior, com equipamentos emprestados pela própria universidade.

O espaço foi palco para diversos tipos de intervenções musicais, poéticas, pirofágicas

\footnotetext{
${ }^{8}$ Mestranda em Artes, Urbanidades e Sustentabilidade pela Universidade Federal de São João del-Rei. Licenciada em Artes Visuais pela Faculdades Santa Marcelina (2014) e graduada em Desenho de Moda também pela Faculdades Santa Marcelina (2004). Fundadora e arte-educadora na Atelierista (MG), espaço informal dedicado à educação especial inclusiva, ao atendimento de pessoas com necessidades educativas especiais com foco no desenvolvimento de habilidades motoras e socioemocionais através da arte.

${ }^{9}$ Coletivo independente composto por jovens artistas da cidade e da universidade.
} 
e inclusive uma pequena iniciação aos equipamentos aéreos do circo, como a lira e o tecido. Enquanto o evento acontecia, montamos um espaço dentro do Fortim do Emboabas onde dispusemos as doações para quem quisesse levar. Entre roupas e brinquedos, doamos também produtos de higiene pessoal e material escolar, itens que foram abordados durante reuniões com a comunidade. Concluímos o evento com um freestyle de encerramento entre os artistas e com os espectadores, tornando a Zona Autônoma Temporária, mais um vez, apenas um lugar ideal de possibilidade.

\section{RESULTADOS E DISCUSSÃO}

Terminamos o ano de 2019 com uma extensa bagagem de ações ecopoéticas com o corpo-quebrada. E na errância performativa, conseguimos o apoio de moradores que se dispuseram a ajudar voluntariamente nos projetos futuros em prol da comunidade onde vivem. Um engajamento social que une as forças locais para a criação autônoma de um fazer cotidiano que sustenta a vida em comunidade e promove o bem estar social.

Devemos muitas considerações à moradora e voluntária do projeto Josiane Saldanha, que acolheu e abraçou nossas ideias com muito empenho e dedicação e nos ajudou a estreitar a comunicação na região para que os eventos pudessem ser realizados, além de ajudar na manutenção da relação entre o Laboratório de Ecopoéticas e a comunidade nas mídias sociais.

$\mathrm{O}$ ano de 2020, quando a pandemia Sars-CoV-2 se alastrou pelo mundo, tornou a continuação in loco do projeto inviável, mas mantivemos contato com os moradores através da internet. E por causa das redes sociais e o compromisso dos voluntários do projeto, executamos ações ativistas para arrecadar alimentos, marmitas e roupas de frio para os moradores mais carentes da região, sem colocar em risco as pessoas que participaram dessa iniciativa. Por fim, ressaltamos a importância da comunicação artivista nas comunidades, seja lá qual abordagem for utilizada no processo, principalmente durante esse momento pandêmico que o mundo vive, pois assim podemos preservar, sustentar, promover e evidenciar a vida de pessoas que estão em regiões periféricas e invisibilizadas. 


\section{REFERÊNCIAS}

ARRUZZA, C.; Bhattacharya, T.; Fraser, N.Feminismo para os 99\%: um manifesto. São Paulo: Boitempo, 2019.

BEY, Hakim. (ZAT) Zona Autônoma Temporária. Trad. Patricia Decia e Renato Rezende, Coletivo Sabotagem, 2004. Disponível em: https://midiatatica.desarquivo.org/2002-2005/taz/ . Acesso em 22 set 2020.

DEBORD, Guy. Teoria da Deriva. Internacional Situacionista, $\mathrm{n}^{\circ} .2,1958$. Disponível em: https://bibliotecaanarquista.org/library/guy-debord-teoria-da-deriva .Acesso em 20 out 2020.

DELEUZE, G.; GUATTARI, F., Mil Platôs (Capitalismo e Esquizofrenia). Vol. 1. Editora 34, 1 ${ }^{\text {a }}$ Ed. 1995.

FÉRAL, Josette. Por uma poética da performatividade: o teatro performativo. Sala Preta, Revista do Programa de Pós-Graduação em Artes Cênicas, Eca/USP, São Paulo, n. 08, 2008, p. 197-210. Disponível em: https://www.revistas.usp.br/salapreta/article/view/57370. Acesso em: 18 out 2020.

FERNANDES, Ciane. Movimento e Memória: Manifesto da Pesquisa Somático-Performativa. Salvador: UFBA, 2012. Disponível em: https://www.publionline. iar.unicamp.br/index.php/abrace/article/view/2546. Acesso em: 6 out 2020.

FERNANDES, C. Pesquisa Somático-Performativa: Sintonia, Sensibilidade, Integração. ARJ - Art Research Journal / Revista de Pesquisa em Artes, v. 1, n. 2, p. 76-95. Disponível em: https://periodicos.ufrn.br/artresearchjournal/article/ view/5262. Acesso em: 6 out 2020.

FISCHER-LICHTE, Érika. The transformative power of performance - a new aesthetics. Londres e Nova York: Routledge, 2008.

JACQUES, Paola Beresntein (org.). Apologia da Deriva: escritos situacionistas sobre a cidade. Rio de Janeiro: Casa da Palavra, 2003.

KASTRUP, Virgínia (org.). Pistas do método da cartografia: Pesquisa-intervenção produção de subjetividade. Porto Alegre, Sulina, 2010.

ROMAGNOLI, Roberta Carvalho. O conceito de implicação e a pesquisa-intervenção institucionalista. Psicol. Soc., Belo Horizonte, v. 26, n. 1, p. 44-52, Abril. 2014. 
Disponível em: http://www.scielo.br/scielo.php?script=sci_arttext\&pid=S0102$-71822014000100006 \& \operatorname{lng}=$ en $\& n r m=$ iso. Acesso em: 8 out 2020.

SCHECHNER, Richard. “What's performance?”, em Performance studies: an introduction, second edition. New York \& London: Routledge, 2006.

SIQUEIRA, Adilson. Arte e Sustentabilidade: Argumentos para a pesquisa Ecopoética da cena. MORINGA - teatro e dança; Vol 1, No 1, 2010. Disponível em: https://periodicos.ufpb.br/ojs2/index.php/moringa/article/view/4800. Acesso em 20 nov 2020.

VIEIRA, Teresa. Artivismo: estratégias artísticas contemporâneas de resistência cultural. Porto Alegre: FBAUP, 2007. Disponível em: https://repositorio-aberto. up.pt/handle/10216/7307. Acesso em: 8 out 2020.

SIQUEIRA, Adilson; MONTEIRO, Carolina, RELOCALIZAÇÃO ECONÔMICA E ECOPOÉTICA: definições, dimensões e proposição de ação artivista. Revista Humus, vol. 7, num. 23, 2018. pp. 126-150. Disponível em: http://www.periodicoseletronicos.ufma.br/index.php/revistahumus/article/view/9632. Acesso em: 22 set 2020 .

SIQUEIRA, Adilson Roberto. Busca e retomada: um processo de treinamento para a construção da personagem pelo ator-dançarino. 2000. 290 p. Dissertação (mestrado) - Universidade Estadual de Campinas. Instituto de Artes, Campinas, SP. Disponível em: http://www.repositorio.unicamp.br/handle/REPOSIP/284884>. Acesso em: 9 out. 2020. 


\begin{abstract}
Since 2018, ECOLAB has been investigating the possibilities of creating Temporary Autonomous Zones (TAZ), in the Rua do Ouro community, located in the Alto das Mêrces region, in São João do Rei, seeking to apply its own methodology, based on the cartographic-somatic-performative-ecopoetic to the creation of spaces of possibilities.
\end{abstract}

\title{
Keywords
}

Performance. Ecopoetics. Event.

Recebido em: 13 out. 2020

Aceito em: 19 nov. 2020

Publicado em: 23 dez. 2020 